\title{
Characteristic of a GH10 Xylanase From The Anaerobic Rumen Fungus Anaeromyces Robustus and Application in Bread Making
}

Zhenyang Liu

Yangtze University

Sitao Wen

Yangtze University

Guogan Wu

Shanghai Academy of Agricultural Sciences

Huawei Wu ( $D$ wuhuawei-2000@163.com )

Yangtze University

Research Article

Keywords: Xylanase, Pichia pastoris, Ruminal microorganisms, Anaeromyces robustus, Bread

Posted Date: August 9th, 2021

DOI: https://doi.org/10.21203/rs.3.rs-736962/v1

License: (c) (i) This work is licensed under a Creative Commons Attribution 4.0 International License.

Read Full License 


\section{Characteristic of a GH10 xylanase from the anaerobic rumen fungus Anaeromyces robustus and application in bread making}

Zhenyang Liu ${ }^{1}$, Sitao $\mathrm{Wen}^{1}$, Guogan $\mathrm{Wu}^{2}$, Huawei $\mathrm{Wu}^{1 *}$

\section{Abstract}

The rumen of ruminants contains a variety of fungi capable of producing xylanases to break down plant cell walls. In this study, a new GH10 xylanase gene ArXyn10c20 from anaerobic rumen microorganism Anaeromyces robustus was successfully expressed in Pichia Pastoris GS115, with a protein molecular weight of approximately $42 \mathrm{kDa}$ and showed the similarity by $64.08 \%$ with the $\beta$-Xylanase form Neocallimastix Californiae. The optimal $\mathrm{pH}$ and temperature for ArXyn $10 \mathrm{c} 20$ was 5.5 at $40^{\circ} \mathrm{C}$. ArXyn10c20 was stable in the $\mathrm{pH}$ range $5.0-9.0$ for $1 \mathrm{~h}$ which the residual enzyme activity was all above $75 \%$. The activity of recombinant xylanase was significantly enhanced by $1 \mathrm{mM} \mathrm{Cu}^{2+}$. The products of ArXyn10c20 hydrolysis of beechwood xylan were xylobiose, xylotriose and xylotetraose by TLC analysis. In food applications, ArXyn10c20 can significantly improve the quality of dough and bread. With the addition of $7.5 \mathrm{mg}$ ArXyn10c20, the hardness, gumminess and chewiness of the bread decreased by $42.24 \%, 45.33 \%$ and $55.36 \%$ respectively and the reducing sugar increased by $18.67 \%$. The new discovered xylanase ArXyn10c20 has great potential in food industry.

\section{Keywords}

Xylanase, Pichia pastoris, Ruminal microorganisms, Anaeromyces robustus, Bread 


\section{Introduction}

Anaerobic fungi found in the rumen of ruminants are an excellent source of xylanase. Ruminal fungi were first discovered in 1975 and are the only known group of anaerobic fungi. To date, more than 20 species have been successfully isolated, including six genera: Piromyces, Anaeromyces, Neocallimastix, Cyllamyces, Caecomyes, and Orpinomyces. The first genome sequencing of anaerobic rumen fungi was completed in 2013 [1], with Anaeromyces robustus being classified in 2016 [2]. Ruminal anaerobic fungi are highly adapted to fibre degradation, which is important for the degradation of difficult to process biological resources currently encountered in industry $[3,4]$. Among rumen microorganisms, fungi take a small percentage, but play an important role in the degradation of xylan in plant cell walls by ruminants [5].

Xylan is an important component of plant hemicellulose, which accounts for one third of the total plant carbohydrates and is the second most abundant in nature after cellulose [6]. Xylan is found in the cell walls of terrestrial plants and is present in almost all parts of the plant. The amount of xylan in different plants varies, generally more in hardwoods than in softwoods, accounting for $15 \%-30 \%$ of the dry weight in hardwoods and $7 \%-10 \%$ in softwoods. In some annual plants, such as wheat, sugarcane and cotton, the xylan content is very high, generally up to $30 \%$ or more [7].

Xylanase is a general term for enzymes that degrade xylan. $\beta$-xylanase, $\beta-1,4-$ endo-xylanase, and $\alpha$-L-arabinosidase all belong to xylanase. Among all xylanases, $\beta$ 1,4-endo-xylanase (EC 3.2.1.8) plays the main degradation function. In the hydrolysis process, xylanase mainly breaks the $\beta$-1,4-glycosidic bond of xylan to hydrolyze it into 
xylose and other oligosaccharides [8]. Oligosaccharides are finally degraded into xylose by the action of $\beta$-xylosidase, and other enzymes in xylanase such as acetylxylan esterase and other side chain hydrolases usually have synergistic effects on the main chain hydrolases. Through the cooperation of multiple enzymes finally hydrolyze xylan into xylose [9].

Based on a comparison of structures at the catalytic domain level, almost all xylanases to date have been grouped into the glycoside hydrolase family $(\mathrm{GH}) 5,8,10$, 11, 43, 62 [10]. Most of xylanases were classified into GH10 and GH11. Xylanase can be produced by plants, animals and microorganisms [11], but the nature xylanase produced differs depending on the type of producer. Bacterial-derived xylanases have an advantage over fungal-derived xylanases in terms of heat resistance [12]. Among all xylanase producing microorganisms, rumen fungi are a very special group and currently, less than $10 \%$ of rumen fungi can be isolated by pure culture techniques [13]. Therefore, there is an increasing use of macro-genomic techniques to research rumen fungi [14].

Xylan is widely used in the food, medical and chemical industries. Xylan can be added to food as a dietary additive or used as a raw material in the production of oligosaccharides or xylitol [15]. Its high water-holding capacity allows it to be used in biomedical applications such as drug delivery [16]. In addition, xylan is used as a renewable and biodegradable plant resource in chemical applications such as the production of 5-hydroxymethylfurfural (HMF), furfural, ethanol or other value-added chemicals [17]. 


\section{Materials and Methods}

\section{Strains and reagents}

Pichia pastoris GS115 and Escherichia coli DH5 $\alpha$ was preserved in our laboratory. G418 and biotin were purchased from Macklin (Shanghai, China) and used for the construction of recombinant P. pastoris strains. SnaBI, SalI, NotI were purchased from Takara (Dalian, China), EnDo H was purchased from New England Biolabs (Beijing, China). Beechwood xylan was purchased from Shanghai Yuanye Bio-Technology (Shanghai, China). Xylose, xylobiose, xylotriose, xylotetraose, and xylopentaose were purchased from Solarbio (Beijing, China) for thin layer chromatography. Silica gel plate GF254 was purchased from Qingdao Haiyang Chemical (Qingdao, China).

\section{Construction of recombinant plasmid pPIC9K-ArXyn10c20}

The GH10 xylanase gene sequence of strain Anaeromyces robustus (GenBank: ORX71682.1) was found at the Uniprot server and synthesized by GENWIZ with codon optimization, it was amplified by two primers ArXyn10c20F (5'TACGTAGAGATTGGATTGAGGGAAT-3') and ArXyn10c20R (5'GCGGCCGCTTAATGGTGAT-3'), and inserted into pPIC9K to construct the recombinant plasmid pPIC9K-ArXyn10c20.

\section{Transformation and expression of ArXyn10c20 in P. pastoris GS115}

The pPIC9K-ArXyn10c20 was linearized by SalI and transformed into P. pastoris GS115 by electroporation. The recombinant strains were cultured on MD plates and then the transformants were cultured on YPD plates with G418 $(0.25-2.0 \mathrm{mg} / \mathrm{ml})$. The transformants that grew normally on YPD plates were further incubated in 5mL BMGY 
medium for 2 days, cells were collected and incubated in $50 \mathrm{~mL}$ BMMY medium for 4-5 days. The transformants were determined by xylanase activity assay and SDSPAGE.

\section{Sequence analysis and structure prediction}

Sequence alignments and homology searches were performed by BLASTP at NCBI (https://blast.ncbi.nlm.nih.gov/Blast.cgi). The protein sequences were analyzed on Expasy (https://blast.ncbi.nlm.nih.gov/Blast.cgi) to predict isoelectric sites and hydrophobicity, glycosylation analysis was performed on NetNGlyc server (http://www.cbs.dtu.dk/services/NetNGlyc/). The sequences with $35 \%-60.1 \%$ similarity to the ArXyn10c20 were used to construct phylogenetic tree by MEGA5.2 (https://www.megasoftware.net/index.php). Structure model was generated on SWISSMODEL (https://swissmodel.expasy.org/interactive), and the structural figures were analyzed by ESPript3.0 and performed by SPDBV program (https://spdbv.vital-it.ch/).

\section{Purification and deglycosylation of ArXyn10c20}

The culture was centrifuged at $5000 \times \mathrm{g}, 4^{\circ} \mathrm{C}$ for $10 \mathrm{~min}$ to collect the supernatant and purified by Ni-NTA resin. The protein was eluted with elution buffer $(0.25 \mathrm{M} \mathrm{NaCl}$, and $20 \mathrm{mM}$ Tris- $\mathrm{HCl}$ buffer, $0.2 \mathrm{M}$ imidazole, $\mathrm{pH}$ 6.5). Endo $\mathrm{H}$ was used to remove $\mathrm{N}$ linked glycan of purified ArXyn10c20. SDS-PAGE was performed to detect the degree of ArXyn10c20 glycosylation.

\section{Enzyme activity assay}

The enzyme activity of xylanase was determined by the DNS method [18]. The reaction solution contained $90 \mu \mathrm{L} 1 \%(\mathrm{~W} / \mathrm{V})$ beechwood xylan and $30 \mu \mathrm{L}$ diluted 
enzyme and incubated at $\mathrm{pH} 5.5$ and $40^{\circ} \mathrm{C}$ for 30 minutes. After $180 \mu \mathrm{L}$ of DNS was added to the reaction, the mixture was boiled for $5 \mathrm{~min}, 1.2 \mathrm{~mL}$ deionized water was added to set the volume to $1.5 \mathrm{~mL}$. The released reducing sugar was quantified by spectrometric method at $540 \mathrm{~nm}$. All determinations of ArXyn10c20 activity were performed in triplicate. The xylanase required to degrade beech xylan to produce 1 $\mu \mathrm{mol}$ xylose per minute at $\mathrm{pH} 5.5$ and $40^{\circ} \mathrm{C}$ was defined as one unit of enzyme activity.

\section{Effects of pH and temperature on ArXyn10c20 activity and stability}

The optimal $\mathrm{pH}$ of purified ArXyn 10 was determined at $40^{\circ} \mathrm{C}$ in $50 \mathrm{mM}$ different citric acid/sodium citrate buffers at the $\mathrm{pH}$ range of 3.0-6.5 and in $50 \mathrm{mM}$ different Tris- $\mathrm{HCl}$ buffers at the $\mathrm{pH}$ range of 7.0-9.0. The $\mathrm{pH}$ stability was determined after treatment for 5-60 minutes at $\mathrm{pH}$ range 3.0 to 9.0 and dilution with $0.1 \mathrm{M}$ citric acid/sodium citrate buffer at $\mathrm{pH}$ 5.5. Residual activity was determined by activity assay and calculated relative activity using the untreated sample as control $(100 \%)$.

The optimum temperature of ArXyn10c20 was determined at $\mathrm{pH} 5.5$ in the temperature range $30^{\circ} \mathrm{C}-80^{\circ} \mathrm{C}$. The thermostability of $\operatorname{ArXyn} 10 \mathrm{c} 20$ was determined by treatment at $50^{\circ} \mathrm{C}, 60^{\circ} \mathrm{C}$ and $70^{\circ} \mathrm{C}$ for $5-60$ minutes, respectively. The residual activity was determined by activity assay and the relative activity was calculated as above.

\section{Effect of metal ions and chemicals on the ArXyn10c20 activity}

To determine the effect of metal ions and chemicals on ArXyn10c20 activity, final concentrations of $1 \mathrm{mM}$ and $5 \mathrm{mM}$ of $\mathrm{Na}^{+}, \mathrm{K}^{+}, \mathrm{Ca}^{2+}, \mathrm{Cu}^{2+}, \mathrm{Mn}^{2+}, \mathrm{Zn}^{2+}, \mathrm{Cu}^{2+}, \mathrm{Mg}^{2+}$, $\mathrm{Co}^{2+}$, SDS, and EDTA were added to the reaction solution, respectively. Reaction solutions without metal ions and chemicals were used as control. The residual activity 
was determined by activity assay and the relative activity was calculated as above.

\section{Substrate specificity and kinetic of ArXyn10c20}

The kinetic parameters of ArXyn10c20 were determined using different concentrations of beechwood xylan $(1 \mathrm{mg} / \mathrm{mL}, 2 \mathrm{mg} / \mathrm{mL}, 2.5 \mathrm{mg} / \mathrm{mL}, 3.3 \mathrm{mg} / \mathrm{mL}, 5$ $\mathrm{mg} / \mathrm{mL}, 10 \mathrm{mg} / \mathrm{mL}$ ) in the reaction system. the $\mathrm{K}_{\mathrm{m}}, \mathrm{V}_{\max }$ and $\mathrm{k}_{\text {cat }}$ values of ArXyn10c20 were calculated from Lineweaver-Burk plots, $\mathrm{y}=\mathrm{Vmax} *[\mathrm{~S}] /(\mathrm{Km}+[\mathrm{S}])[19]$.

To test the substrate specificity of ArXyn10c20, beechwood xylan, sodium carboxymethylcellulose $(\mathrm{CMC}-\mathrm{Na})$, microcrystalline cellulose, and filter paper $(2 \times 1$ $\mathrm{cm}$ ) were used as substrates in the standard activity assay to determine enzyme activity and the relative activity of the other substrates was calculated using the enzyme activity of beechwood as substrate as $100 \%$.

\section{Thin-layer chromatography (TLC) assay}

The hydrolysis products were analysed by incubating purified ArXyn10c20 at $\mathrm{pH}$ 5.5 and $40^{\circ} \mathrm{C}$ for 30 minutes with $1.0 \%(\mathrm{w} / \mathrm{v})$ beechwood xylan as substrate and separated on silica gel plate GF254 for 2 hours. The solvent system included chloroform, acetic acid, and water (6:7:1. V/V/V). After spraying with ethanol: sulfuric acid (95:5, $\mathrm{V} / \mathrm{V}$ ) solvent, the reducing sugars were visualized by heating at $105^{\circ} \mathrm{C}$ for $5 \min [20]$. A mixture consisting of xylose (X1), xylobiose (X2), xylotriose (X3), xylotetraose (X4) and xylopentaose (X5) was used as standard.

\section{Application of ArXyn10c20 in bread making}

The recipe for bread was as follows: $100 \mathrm{~g}$ high-gluten wheat flour, $60 \mathrm{~mL}$ water, $10 \mathrm{~g}$ sugar, $5 \mathrm{~g}$ butter, $0.3 \mathrm{~g}$ yeast (Instant dry yeast, Saccharomyces cerevisiae, Angel 
Yeast Co., Ltd), $1 \mathrm{~g}$ salt. The bread making process was to knead the dough for $15 \mathrm{~min}$ and to rest at $40^{\circ} \mathrm{C}, 80 \%$ humidity for $2 \mathrm{~h}$, take out and divide the dough into $50 \mathrm{~g}$ for each one, then rest for $1 \mathrm{~h}$, and bake for $30 \mathrm{~min}\left(\right.$ Upper tube at $160^{\circ} \mathrm{C}$, lower tube at $\left.180^{\circ} \mathrm{C}\right)$

$0 \mathrm{mg}$ (control), $2.5 \mathrm{mg}, 5 \mathrm{mg}$ and $7.5 \mathrm{mg}$ of purified ArXyn10c20 was added into dough to make bread, respectively, and specific volume, texture, and reducing sugar content were determined. The specific volume was tested by the rapeseed substitution method [21]: Put the bread into a beaker, fill it with rapeseed, shake it thoroughly to expel the air and record the volume V1, take the bread out and record the volume V2, the volume of the bread V=V1-V2. The mass of the bread is weighed on the electronic balance as $\mathrm{m}$. Specific volume $\mathrm{v}=\mathrm{V} / \mathrm{m}$. The texture was measured by texture analyzer (TMS-PRO) and the bread was sliced to a thickness of $10 \mathrm{~mm}$. The reducing sugar content was determined using the supernatant of the dough by DNS method as above. The supernatant was obtained by dissolving $10 \mathrm{~g}$ of dough in $100 \mathrm{ml}$ of water, mixing thoroughly and centrifuging.

\section{Effect of ArXyn10c20 on microstructure of dough}

The dough was pressed onto a slide and observed and photographed on an optical microscope (apparatus model Olympus BX63, Yangtze University, Jingzhou, China) using a $100 \times$ oil microscope.

The dough was freeze-dried and exposed to gold sputtering. The samples were then observed and photographed with a scanning electron micrograph (apparatus model TM4000, Shanghai Academy of Agricultural Sciences, Shanghai, China) at an 
accelerating voltage of $5 \mathrm{kV}$.

\section{Results and discussion}

\section{Sequence and structure analysis}

This is the first time that ArXyn10c20 has been isolated from an anaerobic rumen fungus and heterologously expressed in P. pastoris GS115. Through sequence alignment, the $\beta$-xylanase from Neocallimastix californiae was the most similar to Arxyn10c20 with $64.08 \%$ identity (GenBank: ORY30865.1), indicating that ArXyn10c20 produced by Anaeromyces robustus is a new GH10 xylanase. A phylogenetic tree was constructed using xylanases with $35 \%-64.08 \%$ identity to ArXyn10c20 (Fig. 1.). It showed in the tree that ArXyn10 evolved as an independent branch, and it was most close to the branch including the xylanases from $N$. californiae. It was the first discovered xylanase identified from $A$. robustus, which enriched the source of xylanases and may had important meanings for the study of xylanases from anaerobic origins.

Structure of GH10 xylanase usually had $(\alpha / \beta)_{8}$ TIM-barrel folds [22], which was consistent with the homology modeling structure of ArXyn10c20 (Fig. 2.). SwissModel was used to perform homology modeling of proteins. ArXyn10c20 shared the high identity of $36.51 \%$ with chimeric xylanase (1v6y.1.A) between Streptomyces Olivaceoviridis E-86 FXYN and Cellulomonas fimi Cex.

The multiple sequence comparisons of several GH10 xylanases produced by rumen microorganisms revealed that their catalytic sites are highly consistent and their relative positions in the GH10 domain was conservative (Fig. 3.). In the model of 
ArXyn10c20, the catalytic sites located at the inner edge of the depression of the bowlshaped structure formed by the $(\alpha / \beta)_{8}$ TIM-barrel structure. E144 and E260 were speculated as catalytic sites in ArXyn10c20, were the key amino acids for xylanase activity in this study.

\section{Expression and purification of ArXyn10c20}

Analysis of the protein sequence showed that 18 amino acids at the N-terminus of the protein were signal peptides, amino acid (AA) 16-332 was GH10 domain. E144 and E260 were catalytical active sites of ArXyn10c20. ArXyn10c20 possessed five possible N-glycosylation sites, N36, N267, N304, N337 and N346, and two possible O-glycosylation sites, T233 and T365.

ArXyn10c20 encoding gene was obtained and cloned into pPIC9K, resulting the recombinant plasmid pPIC9K-ArXyn10c20. ArXyn10c20 comprised 1113 bp with 370 amino acids. After expression in P. pastoris GS115 and purification, the protein sample was analyzed by SDS-PAGE. A single band of ArXyn10c20 was observed near $42 \mathrm{kDa}$ in SDS-PAGE, which was approximately the calculated theoretical size of ArXyn10c20. By determination of the SDS-PAGE and enzyme activity assay, the recombinant protein of ArXyn10c20 was successfully expressed, purified and identified. After digestion by Endo H, the molecular weight of ArXyn10c20 did not change significantly, indicating that ArXyn10c20 was not glycosylated (Fig. 4.).

\section{Characterization of the purified ArXyn10c20}

As shown in Fig. 5., The optimal pH of the purified ArXyn10c20 was 5.5, and ArXyn10c20 maintained more than $90 \%$ of the enzyme activity between $\mathrm{pH} 5.5-6.0$, 
showing it was an acid xylanase. ArXyn10c20 had a wide range of $\mathrm{pH}$ stability. After holding at $\mathrm{pH}$ 5.0-9.0 for $1 \mathrm{~h}$ respectively, the residual enzyme activity was all above $75 \%$.

The optimum temperature of $\operatorname{ArXyn} 10 \mathrm{c} 20$ was $40^{\circ} \mathrm{C}$, and could maintain high enzyme activity at $35-40^{\circ} \mathrm{C}$, indicating that $\mathrm{ArXyn} 10 \mathrm{c} 20$ is a medium temperature enzyme. In the case of high temperature treatment, after holding at $50^{\circ} \mathrm{C}$ for 10 minutes, $21.99 \%$ enzyme activity remained. After holding at $60^{\circ} \mathrm{C}$ for $5 \mathrm{~min}$, the enzyme activity was only $10.08 \%$ remained. When treated at $70^{\circ} \mathrm{C}$, less then $5 \%$ enzyme activity remained, indicating that the protein is not resistant to high temperatures.

The optimum temperature of ArXyn10c20 is consistent with the fermentation temperature of yeast and is ideal for applications in food, such as bread making. For other applications, ArXyn10c20 needs to be modified as it has good pH stability but poor thermal stability.

Compared to other xylanases, ArXyn10c20 lacks the CBM domain. Importantly, the presence of some CBM domains enhances the thermal stability of the protein. After deleting the C-terminal CBM, the mutant obtained greater substrate affinity and catalytic efficiency, and the thermal stability was also improved [23]. To improve the enzymatic activity and stability of ArXyn10c20, the addition of a thermally stable CBM domain could be considered.

The effects of different metal ions and chemical reagents on the activity of ArXyn10c20 were shown in Table 1. Under the condition of low concentration (1 mM), ArXyn10c20 was slightly enhanced by $\mathrm{Co}^{2+}(109.42 \%), \mathrm{Cu}^{2+}(112.86 \%), \mathrm{Ba}^{2+}$ 
(123.94\%), moderately inhibited by $\mathrm{Mn}^{2+}(72.50 \%)$, SDS (72.12\%). At high concentration $(5 \mathrm{mM}), \operatorname{ArXyn} 10 \mathrm{c} 20$ was significantly activated by $\mathrm{Ca}^{2+}(137.60 \%)$, $\mathrm{Ba}^{2+}(204.79 \%)$, moderately inhibited by $\mathrm{Co}^{2+}(81.97 \%), \mathrm{Mg}^{2+}(81.97 \%)$, EDTA (72.77\%), $\mathrm{Zn}^{2+}(67.59 \%), \mathrm{Mn}^{2+}(62.52 \%), \mathrm{Cu}^{2+}(46.84 \%)$.

Setting the enzyme activity for beechwood xylan as $100 \%$, the enzyme activities of filter paper was $4.38 \%$, and it showed no activity on soluble starch 、 CMC-Na and microcrystalline cellulose, exhibited a high degree of substrate specificity. Although GH10 family xylanases are able to hydrolyse a wider range of substrates than GH11 family xylanases [24], they do not have cellulase activity, whereas GH11 family xylanases have cellulase activity.

The kinetic parameters of ArXyn10c20 were obtained by Lineweaver-Burk plot. $\mathrm{V}_{\max }$ and $\mathrm{K}_{\mathrm{m}}$ were $250.00 \mathrm{U} / \mathrm{mg}$ and $6.975 \mathrm{mg} / \mathrm{mL}, \mathrm{K}_{\text {cat }}$ was $175.40 \mathrm{~s}^{-1}$, and $\mathrm{K}_{\text {cat }} / \mathrm{K}_{\mathrm{m}}$ was $25.15 \mathrm{~s}^{-1} \cdot(\mathrm{mg} / \mathrm{mL})^{-1}$. As shown in Table 2 , the $\mathrm{K}_{\mathrm{m}}, \mathrm{K}_{\text {cat }}$ and $\mathrm{K}_{\text {cat }} / \mathrm{K}_{\mathrm{m}}$ of ArXyn10c20 are higher than those of other GH10 family xylanases, showing excellent catalytic activity and efficiency.

\section{Thin-layer chromatography (TLC) assay}

The hydrolysis products of ArXyn10c20 on beechwood xylan were analyzed by TLC and the results showed that the products were xylobiose (X2), xylotriose (X3) and xylotetraose (X4) (Fig. 6.).

Based on food applications, oligosaccharides with a polymerisation degree of 2-4 were preferred [29], making ArXyn10c20 suitable for use in food applications. In addition, xylooligosaccharides $(\mathrm{X} 2-\mathrm{X} 7)$ are known to improve the intestinal 
environment [30], inhibit pathogenic bacteria, prevent constipation, protect liver function, lower serum cholesterol and blood pressure, and effectively promote the activity of Bifidobacteria [31]. Xylooligosaccharides are becoming increasingly important in areas such as human health, anti-cancer and clean energy conversion [32].

\section{Application of ArXyn10c20 in bread making}

The specific volume of the bread was 2.2 without the addition of ArXyn10c20, while the specific volume of the bread was $2.63,2.59$ and 2.80 with the addition of 2.5 $\mathrm{mg}, 5.0 \mathrm{mg}$ and $7.5 \mathrm{mg}$ ArXyn10c20 respectively. It is showed that ArXyn10c20 could improve the dough quality and increase the volume of the bread. By measuring the texture of the bread, the hardness, gumminess and chewiness of the bread decreased with the increase of ArXyn10c20 addition (Table 3), and the taste of the bread was improved. After the addition of $2.5 \mathrm{mg}$ ArXyn10c20, the hardness, gumminess and chewiness of the bread decreased by $25.86 \%, 32.00 \%$ and $13.10 \%$ respectively, while the addition of $7.5 \mathrm{mg}$ decreased by $42.24 \%, 45.33 \%$ and $55.36 \%$ respectively, indicating that ArXyn10c20 can significantly improve the quality of dough and bread. Comparing the effects of different xylanases on the chewiness and hardness of bread, ArXyn10c20 significantly reduced the chewiness and hardness of bread at a low addition level (Table 4).

As shown in Fig. 7, with the addition of $2.5 \mathrm{mg}$ ArXyn10c20, gluten network formation was minimal and not significantly different from the control. Gluten network formation started at $5.0 \mathrm{mg}$ of ArXyn10c20 addition. With the addition of $7.5 \mathrm{mg}$ ArXyn10c20, gluten network was formed on the whole surface of the dough, and water- 
unextractable arabinoxylan (WUAX) was hydrolysed to small molecules like waterextractable arabinoxylan (WEAX) and xylooligosaccharides.

Bread quality is mainly determined by the dough's ability to produce and hold air. Although the insoluble WUAX content of the flour is about $1.7 \%$ [38], it cannot be directly used by yeast. With the addition of xylanase, WUAX can be broken down into WEAX and xylo-oligosaccharides [39]. Yeast is able to use xylo-oligosaccharides, allowing deeper fermentation of the dough and increased gas production. Furthermore, as a major component of the whole wheat dietary fibre fraction, arabinoxylan (AX) significantly influences dough characteristics and quality [40]. WUAX accounts for about $90 \%$ of $A X$ [41]. WUAX is able to adsorb large amounts of water and can directly interfere with gluten formation [42], being broken down increases the free water in the dough and makes it softer. WEAX and xylooligosaccharides produced by the breakdown of WUEX can bind to the proteins in the dough and form gluten [43].

As more gluten network is formed, the dough's ability to hold air increases and therefore the quality of the bread is better [44]. The gluten network gives the dough its unique viscoelastic properties, which in turn determines the quality of the final product such as baked bread and steamed bread [45]. The bubble walls can expand like a small balloon without tearing until the bread is deformed. When carbon dioxide exerts more pressure than the fermenting dough can withstand, the gluten structure weakens, releasing gas and deflating the over-fermented dough, hence the characteristics of a high quality dough that produces a large volume [46], with uniformly fine pores and fluffy. 
In addition, the content of reducing sugars in the bread with $2.5 \mathrm{mg}, 5.0 \mathrm{mg}$ and $7.5 \mathrm{mg}$ of ArXyn $10 \mathrm{c} 20$ increased by $6.95 \%, 16.91 \%$ and $18.67 \%$ respectively compared to the control. The increase in reducing sugars shows the production of oligosaccharides. These oligosaccharides can be used by yeast to improve the air production capacity of the dough. On the other hand, these oligosaccharides not fully used by yeast can enter the human intestine to be used by Bifidobacterium. As an important probiotic in the human body, Bifidobacterium has a variety of functions for human health, such as biological barrier, anti-tumour, immune enhancement and improvement of gastrointestinal function [47], making bread healthier for the human body.

\section{Conclusion}

In this paper, it is the first time that ArXyn10c20 has been isolated from an anaerobic rumen fungus and successfully expressed in P. pastoris GS115. Analysis of SDS-PAGE showed the monomeric form of the recombinant protein in a size consistent with predicted molecular weight of $42 \mathrm{kDa}$. The xylanase ArXyn10c20 was characterized by determination of optimal temperature and $\mathrm{pH}$, thermal and $\mathrm{pH}$ stability, substrate specificity and kinetic constants were also determined. In practical application, the optimum temperature of ArXyn10c20 is consistent with the fermentation temperature of yeast, making ArXyn10c20 suitable for use in food applications. As the amount of ArXyn10c20 added increases, the reducing sugar content within the dough increases and TLC analysis shows that the hydrolysis products of ArXyn10c20 are mainly X2, X3 and X4, and xylooligosaccharides are now becoming a common health supplement and becoming increasingly popular. The addition of ArXyn10c20 at $7.5 \mathrm{mg}$ 
reduced the hardness and chewiness of the bread by $42.24 \%$ and $55.39 \%$ respectively. The addition of ArXyn10c20 makes the bread fluffier and softer, with an improved texture.

Acknowledgments We would like to thank Yangtze University for laboratory and equipment. 


\section{Data availability}

Sequence read data is available in the NCBI database via accession numbers ORX71682.1 for protein and MW692170 for nucleotide. Other supporting data from this study are available from the corresponding authors upon reasonable request.

\section{Funding}

This study was supported by Open Research Fund of the Jiangsu Provincial Key Construction Laboratory of Probiotics Preparation (JSYSZJ2017001).

\section{Author information}

\section{Affiliations}

Zhenyang $\mathrm{Liu}^{1}$, Sitao $\mathrm{Wen}^{1}$, Guogan $\mathrm{Wu}^{2}$, Huawei $\mathrm{Wu}^{1 *}$

${ }^{1}$ Department of Life and Science, Yangtze University, 1 South-Loop Road, Jingzhou 434025, China.

${ }^{2}$ Biotechnology Research Institute, Shanghai Academy of Agricultural Sciences, 2901 Bei Zhai Road, Shanghai, 201106, China.

\section{Contributions}

ZL and SW designed and performed the experiments and wrote the manuscript and analyzed the data. HW and GW conceived the study design and edited the paper. All authors read and approved the final manuscript.

\section{Corresponding author}

Correspondence to Huawei Wu.

E-mail address: wuhuawei-2000@163.com(Huawei Wu)

\section{Ethics declarations}




\section{Ethical statement}

This article does not contain any studies with human participants or animals performed by any of authors.

\section{Consent to Participate}

Not applicable.

\section{Consent for Publication}

Not applicable.

\section{Conflict of interest}

Authors declare that they have no conflict of interest. 


\section{References}

1. Youssef, N. H., Couger, M. B., Struchtemeyer, C. G., Liggenstoffer, A. S., Prade,

R. A., Najar, F. Z., Atiyeh, H. K., Wilkins, M. R. \& Elshahed, M. S. (2013). The genome of the anaerobic fungus Orpinomyces sp. strain $\mathrm{C} 1 \mathrm{~A}$ reveals the unique evolutionary history of a remarkable plant biomass degrader. Applied Microbiology and Biotechnology, 79(15), 4620-34. https://doi.org/10.1128/AEM.00821-13.

2. Li, G. J., Hyde, K. D., Zhao, R. L., Hongsanan, S., Abdel-Aziz, F. A., et al. (2016). Fungal diversity notes 253-366: taxonomic and phylogenetic contributions to fungal taxa. Fungal Diversity, 78, 1-237. https://doi.org/10.1007/s13225-016-0366-9.

3. Edwards, J. E., Forster, R. J., Callaghan, T. M., Dollhofer, V., Dagar, S. S., Cheng, Y., Chang, J., Kittelmann, S., Fliegerova, K., Puniya, A. K., Henske, J. K., Gilmore, S. P., O'Malley, M. A., Griffith, G. W. \& Smidt, H. (2017). PCR and Omics Based Techniques to Study the Diversity, Ecology and Biology of Anaerobic Fungi: Insights, Challenges and Opportunities. Frontiers in Microbiology, 8, 1657. https://doi.org/10.3389/fmicb.2017.01657.

4. Seppälä, S., Solomon, K. V., Gilmore, S. P., Henske, J. K. \& O'Malley, M. A. (2016). Mapping the membrane proteome of anaerobic gut fungi identifies a wealth of carbohydrate binding proteins and transporters. Microbial Cell Factories, 15(1), 212. https://doi.org/10.1186/s12934-016-0611-7.

5. Tiwari, U. P., Chen, H. Y., Kim, S. W. \& Jha, R. (2018). Supplemental effect of xylanase and mannanase on nutrient digestibility and gut health of nursery pigs studied using both in vivo and in vitro models. Animal Feed Science and Technology, 245, 77- 
90. https://doi.org/10.1016/j.anifeedsci.2018.07.002.

6. Han, N., Ma, Y., Mu, Y., Tang, X., Li, J., \& Huang, Z. (2019). Enhancing thermal tolerance of a fungal GH11 xylanase guided by B-factor analysis and multiple sequence alignment. Enzyme and Microbial Technology, 131, 109422. https://doi.org/10.1016/j.enzmictec.2019.109422.

7. Valls, C., Pastor, F., Vidal, T., Roncero, M. B., Díaz, P., Martínez, J., \& Valenzuela, S. V. (2018). Antioxidant activity of xylooligosaccharides produced from glucuronoxylan by Xyn10A and Xyn30D xylanases and eucalyptus autohydrolysates. Carbohydrate Polymers, 194, 43-50. https://doi.org/10.1016/j.carbpol.2018.04.028.

8. Collins, T., Gerday, C., \& Feller, G. (2005). Xylanases, xylanase families and extremophilic xylanases. FEMS Microbiology Reviews, 29(1), 3-23. https://doi.org/10.1016/j.femsre.2004.06.005.

9. Sepulchro, A., Pellegrini, V., Briganti, L., de Araujo, E. A., de Araujo, S. S., \& Polikarpov, I. (2020). Transformation of xylan into value-added biocommodities using Thermobacillus composti GH10 xylanase. Carbohydrate Polymers, 247, 116714. https://doi.org/10.1016/j.carbpol.2020.116714.

10. Al-Darkazali, H., Meevootisom, V., Isarangkul, D., \& Wiyakrutta, S. (2017). Gene Expression and Molecular Characterization of a Xylanase from Chicken Cecum Metagenome. International Journal of Microbiology, 2017, 4018398. https://doi.org/10.1155/2017/4018398.

11. Zheng, F., Huang, J., Liu, X., Hu, H., Long, L., Chen, K., \& Ding, S. (2016). Nand C-terminal truncations of a GH10 xylanase significantly increase its activity and 
thermostability but decrease its SDS resistance. Applied Microbiology and Biotechnology, 100(8), 3555-3565. https://doi.org/10.1007/s00253-015-7176-y.

12. Mechelke, M., Koeck, D. E., Broeker, J., Roessler, B., Krabichler, F., Schwarz, W. H., Zverlov, V. V., \& Liebl, W. (2017). Characterization of the arabinoxylan-degrading machinery of the thermophilic bacterium Herbinix hemicellulosilytica-Six new xylanases, three arabinofuranosidases and one xylosidase. Journal of Biotechnology, 257, 122-130. https://doi.org/10.1016/j.jbiotec.2017.04.023.

13. Krause, D. O., Denman, S. E., Mackie, R. I., Morrison, M., Rae, A. L., Attwood, G. T., \& McSweeney, C. S. (2003). Opportunities to improve fiber degradation in the rumen: microbiology, ecology, and genomics. FEMS Microbiology Reviews, 27(5), 663-693. https://doi.org/10.1016/S0168-6445(03)00072-X.

14. Gong, X., Gruniniger, R. J., Forster, R. J., Teather, R. M., \& McAllister, T. A. (2013). Biochemical analysis of a highly specific, $\mathrm{pH}$ stable xylanase gene identified from a bovine rumen-derived metagenomic library. Applied Microbiology and Biotechnology, 97(6), 2423-2431. https://doi.org/10.1007/s00253-012-4088-y.

15. Mikkonen, K. S., \& Tenkanen, M. (2012). Sustainable food-packaging materials based on future biorefinery products: xylans and mannans. Trends in Food Science \& Technology, 28(2), 90-102. https://doi.org/10.1016/j.tifs.2012.06.012.

16. Gao, C., Ren, J., Zhao, C., Kong, W., Dai, Q., Chen, Q., Liu, C., \& Sun, R. (2016). Xylan-based temperature/pH sensitive hydrogels for drug controlled release. Carbohydrate polymers, 151, 189-197. https://doi.org/10.1016/j.carbpol.2016.05.075.

17. Naidu, D. S., Hlangothi, S. P., \& John, M. J. (2018). Bio-based products from xylan: 
https://doi.org/10.1016/j.carbpol.2017.09.064.

18. de Souza, A. R., de Araújo, G. C., Zanphorlin, L. M., Ruller, R., Franco, F. C., Torres, F. A., Mertens, J. A., Bowman, M. J., Gomes, E., \& Da Silva, R. (2016). Engineering increased thermostability in the GH-10 endo-1,4- $\beta$-xylanase from Thermoascus aurantiacus CBMAI 756. International Journal of Biological Macromolecules, 93(Pt A), 20-26. https://doi.org/10.1016/j.ijbiomac.2016.08.056.

19. Yang, A., Cheng, J., Liu, M., Shangguan, Y., \& Liu, L. (2018). Sandwich fusion of CBM9_2 to enhance xylanase thermostability and activity. International Journal of Biological Macromolecules, 117 , $586-591$. https://doi.org/10.1016/j.ijbiomac.2018.05.199.

20. Kim, J. Y., Nong, G., Rice, J. D., Gallo, M., Preston, J. F., \& Altpeter, F. (2017). In planta production and characterization of a hyperthermostable GH10 xylanase in transgenic sugarcane. Plant Molecular Biology, 93(4-5), 465-478. https://doi.org/10.1007/s11103-016-0573-5.

21. Tebben, L., Chen, G., Tilley, M., \& Li, Y. (2020). Individual effects of enzymes and vital wheat gluten on whole wheat dough and bread properties. Journal of Food Science, 85(12), 4201-4208. https://doi.org/10.1111/1750-3841.15517.

22. Pollet, A., Delcour, J. A., \& Courtin, C. M. (2010). Structural determinants of the substrate specificities of xylanases from different glycoside hydrolase families. Critical $\begin{array}{lll}\text { Reviews } \quad \text { in } \quad \text { Biotechnology, } & \text { 30(3), }\end{array}$ https://doi.org/10.3109/07388551003645599. 
23. Li, Q., Sun, B., Li, X., Xiong, K., Xu, Y., Yang, R., Hou, J., \& Teng, C. (2018). Improvement of the catalytic characteristics of a salt-tolerant GH10 xylanase from Streptomyce rochei L10904. International Journal of Biological Macromolecules, 107(Pt B), 1447-1455. https://doi.org/10.1016/j.ijbiomac.2017.10.013.

24. Paës, G., Berrin, J. G., \& Beaugrand, J. (2012). GH11 xylanases: Structure/function/properties relationships and applications. Biotechnology Advances, 30(3), 564-592. https://doi.org/10.1016/j.biotechadv.2011.10.003.

25. Fan, G., Yang, S., Yan, Q., Guo, Y., Li, Y., \& Jiang, Z. (2014). Characterization of a highly thermostable glycoside hydrolase family 10 xylanase from Malbranchea cinnamomea. International Journal of Biological Macromolecules, 70, 482-489. https://doi.org/10.1016/j.ijbiomac.2014.07.025.

26. Sermsathanaswadi, J., Baramee, S., Tachaapaikoon, C., Pason, P., Ratanakhanokchai, K., \& Kosugi, A. (2017). The family 22 carbohydrate-binding module of bifunctional xylanase/ $\beta$-glucanase Xyn10E from Paenibacillus curdlanolyticus B-6 has an important role in lignocellulose degradation. Enzyme and Microbial Technology, 96, 75-84. https://doi.org/10.1016/j.enzmictec.2016.09.015.

27. Kim, D. Y., Lee, S. H., Lee, M. J., Cho, H. Y., Lee, J. S., Rhee, Y. H., Shin, D. H., Son, K. H., \& Park, H. Y. (2018). Genetic and functional characterization of a novel GH10 endo- $\beta$ - 1,4-xylanase with a ricin-type $\beta$-trefoil domain-like domain from Luteimicrobium xylanilyticum HY-24. International Journal of Biological Macromolecules, 106, 620-628. https://doi.org/10.1016/j.ijbiomac.2017.08.063.

28. Miao, Y., Li, P., Li, G., Liu, D., Druzhinina, I. S., Kubicek, C. P., Shen, Q., \& Zhang, 
R. (2017). Two degradation strategies for overcoming the recalcitrance of natural lignocellulosic xylan by polysaccharides-binding GH10 and GH11 xylanases of filamentous fungi. Environmental Microbiology, 19(3), 1054-1064. https://doi.org/10.1111/1462-2920.13614.

29. Samanta, A. K., Jayapal, N., Jayaram, C., Roy, S., Kolte, A. P., Senani, S., \& Sridhar, M. (2015). Xylooligosaccharides as prebiotics from agricultural by-products: Production and applications. Bioactive Carbohydrates and Dietary Fibre, 5(1), 62-71. https://doi.org/10.1016/j.bcdf.2014.12.003.

30. Joshi, N., Sharma, M., \& Singh, S. P. (2020). Characterization of a novel xylanase from an extreme temperature hot spring metagenome for xylooligosaccharide production. Applied Microbiology and Biotechnology, 104(11), 4889-4901. https://doi.org/10.1007/s00253-020-10562-7.

31. Zheng, F., Song, L., Basit, A., Liu, J., Miao, T., Wen, J., Cao, Y., \& Jiang, W. (2020). An endoxylanase rapidly hydrolyzes xylan into major product xylobiose via transglycosylation of xylose to xylotriose or xylotetraose. Carbohydrate Polymers, 237, 116121. https://doi.org/10.1016/j.carbpol.2020.116121.

32. Mihajlovski, K., Bunti, A., Mili, M., Rajili-Stojanovi, M., \& Dimitrijevi-Brankovi, S. (2021). From Agricultural Waste to Biofuel: Enzymatic Potential of a Bacterial Isolate Streptomyces Fulvissimus Cks7 for Bioethanol Production. Waste and Biomass Valorization, 12(1). https://doi.org/10.1007/s12649-020-00960-3.

33. Sarabhai, S., Tamilselvan, T. \& Prabhasankar, P. (2021). Role of enzymes for improvement in gluten-free foxtail millet bread: IT'S effect on quality, textural, 
rheological and pasting properties. Lwt-Food Science and Technology, 137, 2021, 110365. https://doi.org/10.1016/j.1wt.2020.110365.

34. Ghoshal, G., Shivhare, U. S., \& Banerjee, U. C. (2013). Effect of xylanase on quality attributes of whole-wheat bread. Journal of Food Quality, 36(3), 172-180. https://doi.org/10.1111/jfq.12034.

35. Passarinho, A., Ventorim, R. Z., Maitan-Alfenas, G. P., de Oliveira, E. B., \& Guimarães, V. M. (2019). Engineered GH11 xylanases from Orpinomyces sp. PC-2 improve techno-functional properties of bread dough. Journal of the Science of Food and Agriculture, 99(2), 741-747. https://doi.org/10.1002/jsfa.9242.

36. Zheng, H., Guo, B., Chen, X. L., Fan, S. J., \& Zhang, Y. Z. (2011). Improvement of the quality of wheat bread by addition of glycoside hydrolase family 10 xylanases. Applied Microbiology and Biotechnology, 90(2), 509-515. https://doi.org/10.1007/s00253-011-3088-7.

37. Shah, A. R., Shah, R. K., \& Madamwar, D. (2006). Improvement of the quality of whole wheat bread by supplementation of xylanase from Aspergillus foetidus. Bioresource Technology, 97(16), 2047-2053. https://doi.org/10.1016/j.biortech.2005.10.006.

38. Saulnier, L., Sado, P. E., Branlard, G., Charmet, G. \& Guillon, F. (2007). Wheat arabinoxylans: exploiting variation in amount and composition to develop enhanced varieties. Journal of Cereal Science, 46(3), 261-281. https://doi.org/10.1016/j.jcs.2007.06.014.

39. Both, J., Biduski, B., Gomez, M., Bertolin, T. E., Friedrich, M. T. \& Gutkoski, L. 
C. (2020). Micronized whole wheat flour and xylanase application: dough properties and bread quality. Journal of Food Science and Technology -Mysore-, 1-11. https://doi.org/10.1007/s13197-020-04851-2.

40. Ghoshal, G., Shivhare, U. S., \& Banerjee, U. C. (2017). Rheological properties and microstructure of xylanase containing whole wheat bread dough. Journal of Food Science and Technology, 54(7), 1928-1937. https://doi.org/10.1007/s13197-017-2627-

3.

41. Pitkänen, L., Tuomainen, P., Virkki, L., \& Tenkanen, M. (2011). Molecular characterization and solution properties of enzymatically tailored arabinoxylans. International Journal of Biological Macromolecules, 49(5), 963-969. https://doi.org/10.1016/j.ijbiomac.2011.08.020.

42. Hardt, N. A., Boom, R. M. \& Goot, A. J. (2014). Wheat dough rheology at low water contents and the influence of xylanases. Food Research International, 66, 478484. https://doi.org/10.1016/j.foodres.2014.10.011.

43. Autio K. (2006). Effects of cell wall components on the functionality of wheat gluten. Biotechnology Advances, 24(6), 633-635. https://doi.org/10.1016/j.biotechadv.2006.07.002.

44. Wang, M. W., Hamer, R. J., Vliet, T. V., Gruppen, H., \& Weegels, P. L. (2003). Effect of water unextractable solids on gluten formation and properties: mechanistic considerations. Journal of Cereal Science, 37(1), 55-64. https://doi.org/10.1006/jcrs.2002.0478.

45. Matsushita, K., Santiago, D. M., Noda, T., Tsuboi, K., Kawakami, S., \& Yamauchi, 
H. (2017). The bread making qualities of bread dough supplemented with whole wheat flour and treated with enzymes. Food Science and Technology Research, 23, 403-410. https://doi.org/10.3136/fstr.23.403.

46. Lim, H. J., \& Shin, H. S. (2020). Antimicrobial and Immunomodulatory Effects of Bifidobacterium Strains: A Review. Journal of Microbiology and Biotechnology, 30(12), 1793-1800. https://doi.org/10.4014/jmb.2007.07046. 


\section{Figure captions}

Fig. 1. Phylogenetic tree of ArXyn10c20 based on protein sequence homology.

Fig. 2. Homology modeling of ArXyn10c20(a) and surface structure of ArXyn10c20(b)

Fig. 3. Multiple sequence alignment of ArXyn10c20 and GH10 xylanases derived from anaerobic rumen fungi. Abbreviation of the xylanases and Uniprot accession numbers are as follows: Neocallimastix californiae A0A1Y2B9V5 (N.c.A0A1Y2B9V5), Neocallimastix californiae A0A1Y2EWG4 (N.c.A0A1Y2EWG4), Neocallimastix californiae A0A1Y2F9K7 (N.c.A0A1Y2F9K7), Neocallimastix californiae A0A1Y2B7Y6 (N.c.A0A1Y2B7Y6), Anaeromyces robustus A0A1Y1VRR2 (A.r.A0A1Y1VRR2).

Fig. 4. SDS-PAGE analysis of the purified ArXyn10c20. Lanes: M: Marker; 1: Cultured supernatant; 2. ArXyn10c20 purified by Ni-NTA; 3. ArXyn10 digested with Endo H; 4. Endo $\mathrm{H}$.

Fig. 5. Effect of $\mathrm{pH}$ and temperature on the catalytic activity and stability of the ArXyn10c20. (a) Optimum temperature; (b) Thermostability; (c) Optimum pH; (d) pH stability.

Fig. 6. TLC analysis of hydrolytic products of ArXyn10c20. Lanes: M: the standard xylose (X1) and xylooligosaccharides (X2-X5); 1: the hydrolytic products catalyzed by $\operatorname{ArXyn} 10 \mathrm{c} 20$ at $\mathrm{pH} 5.5$ and $40^{\circ} \mathrm{C}$ for $30 \mathrm{~min}$; 2. xylan without hydrolysis.

Fig. 7. Effect of ArXyn10c20 on microstructure of dough. (a,f)dough without ArXyn10c20 before fermentation; (b,g)dough without ArXyn10c20 after fermentation; (c,h)dough with $2.5 \mathrm{mg}$ ArXyn10c20 after fermentation; (d,i)dough with $5.0 \mathrm{mg}$ ArXyn10c20 after fermentation; 
(e,j)dough with $7.5 \mathrm{mg}$ ArXyn10c20 after fermentation. 
Table 1 Effect of metal ions and chemical reagents at $1 \mathrm{mM}$ and $5 \mathrm{mM}$ on the activities of ArXyn10c20

\begin{tabular}{|c|c|c|}
\hline \multirow{2}{*}{ Ions or chemicals } & \multicolumn{2}{|c|}{ Relative activity (\%) } \\
\hline & $1 \mathrm{mM}$ & $5 \mathrm{mM}$ \\
\hline Control & $100.00 \pm 1.09$ & $100.00 \pm 1.11$ \\
\hline $\mathrm{Na}^{+}$ & $98.09 \pm 0.66$ & $94.70 \pm 0.71$ \\
\hline $\mathrm{K}^{+}$ & $100.38 \pm 2.13$ & $95.76 \pm 0.94$ \\
\hline $\mathrm{Ca}^{2+}$ & $93.38 \pm 4.29$ & $137.60 \pm 2.13$ \\
\hline $\mathrm{Mn}^{2+}$ & $72.50 \pm 1.01$ & $62.52 \pm 2.21$ \\
\hline $\mathrm{Cu}^{2+}$ & $112.86 \pm 2.54$ & $46.84 \pm 1.59$ \\
\hline $\mathrm{Mg}^{2+}$ & $98.98 \pm 1.54$ & $81.97 \pm 0.61$ \\
\hline $\mathrm{Ba}^{2+}$ & $123.94 \pm 2.87$ & $204.79 \pm .856$ \\
\hline $\mathrm{Fe}^{2+}$ & $102.55 \pm 1.17$ & $116.15 \pm 2.16$ \\
\hline $\mathrm{Zn}^{2+}$ & $104.84 \pm 2.87$ & $67.59 \pm 0.89$ \\
\hline $\mathrm{Co}^{2+}$ & $109.42 \pm 2.76$ & $81.97 \pm 3.37$ \\
\hline SDS & $72.12 \pm 3.03$ & $99.06 \pm 1.95$ \\
\hline EDTA & $106.49 \pm 2.75$ & $72.77 \pm 0.94$ \\
\hline
\end{tabular}


Table 2 Kinetic parameters of different GH10 xylanases.

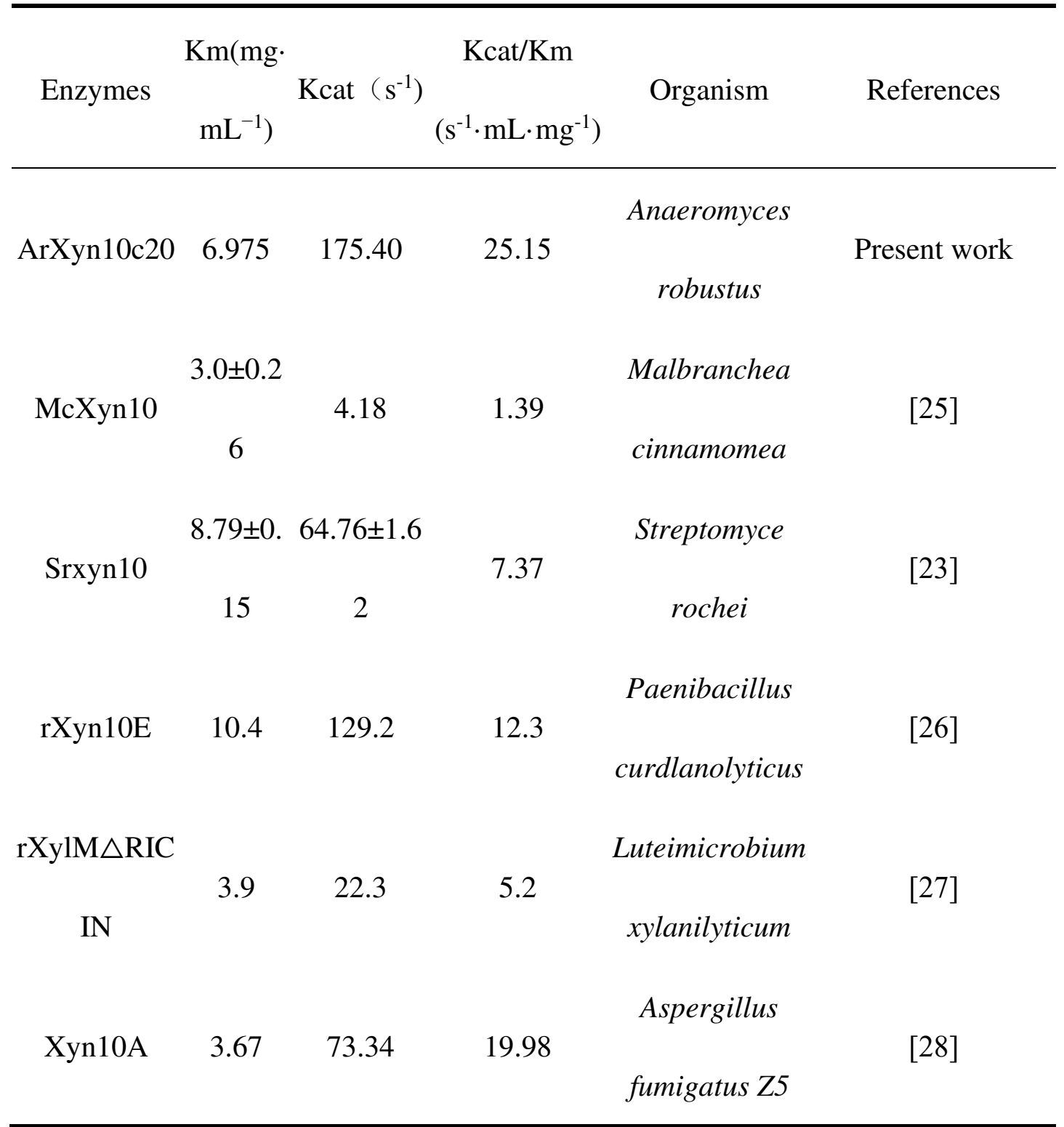


Table 3 Effect of addition of the recombinant xylanase ArXyn10c on the texture of bread

\begin{tabular}{|c|c|c|c|c|c|c|}
\hline ArXyn & Hardness & Adhesiveness & Cohesiveness & Springiness & Gumminess & Chewiness \\
\hline \multicolumn{7}{|l|}{ Control } \\
\hline$(0 \mathrm{mg})$ & 11.6 & 0.29 & 0.65 & 4.06 & 7.5 & 30.51 \\
\hline $2.5 \mathrm{mg}$ & 8.6 & 0.37 & 0.61 & 4.10 & 5.1 & 26.51 \\
\hline $5.0 \mathrm{mg}$ & 6.8 & 0.38 & 0.55 & 4.25 & 4.2 & 15.88 \\
\hline $7.5 \mathrm{mg}$ & 6.7 & 0.30 & 0.61 & 4.33 & 4.1 & 13.61 \\
\hline
\end{tabular}


Table 4 Effect of xylanases on hardness and chewiness of bread

\begin{tabular}{|c|c|c|c|c|}
\hline Xylanase & Dosage & Hardness & Chewiness & References \\
\hline ArXyn10c20 & $25 \mathrm{mg} / \mathrm{kg}$ & $-25.86 \%$ & $-13.11 \%$ & Present work \\
\hline ArXyn10c20 & $50 \mathrm{mg} / \mathrm{kg}$ & $-41.38 \%$ & $-47.95 \%$ & Present work \\
\hline ArXyn10c20 & $75 \mathrm{mg} / \mathrm{kg}$ & $-42.24 \%$ & $-55.39 \%$ & Present work \\
\hline \multirow[t]{2}{*}{ Commercial xylanase } & $500 \mathrm{mg} / \mathrm{kg}$ & $-13.65 \%$ & $+15.06 \%$ & [33] \\
\hline & $1000 \mathrm{mg} / \mathrm{kg}$ & $-36.50 \%$ & $-60.24 \%$ & [33] \\
\hline Extracted xylanase & $0.1 \mathrm{~mL} / \mathrm{kg}$ & $-15.00 \%$ & $+2.42 \%$ & [34] \\
\hline SWT & $1000 \mathrm{U} / \mathrm{kg}$ & $-54.24 \%$ & $-58.91 \%$ & {$[35]$} \\
\hline SM2 & $1000 \mathrm{U} / \mathrm{kg}$ & $-59.57 \%$ & $-61.34 \%$ & [35] \\
\hline XynA & $0.3 \mathrm{U} / \mathrm{kg}$ & $-4.91 \%$ & $+5.23 \%$ & [36] \\
\hline XynA & $0.9 \mathrm{U} / \mathrm{kg}$ & $-7.82 \%$ & $+12.98 \%$ & {$[36]$} \\
\hline XynA & $1.5 \mathrm{U} / \mathrm{kg}$ & $-1.40 \%$ & $+2.13 \%$ & [36] \\
\hline Extracted xylanase & $12000 \mathrm{U} / \mathrm{kg}$ & $-77.27 \%$ & $-35.23 \%$ & [37] \\
\hline
\end{tabular}




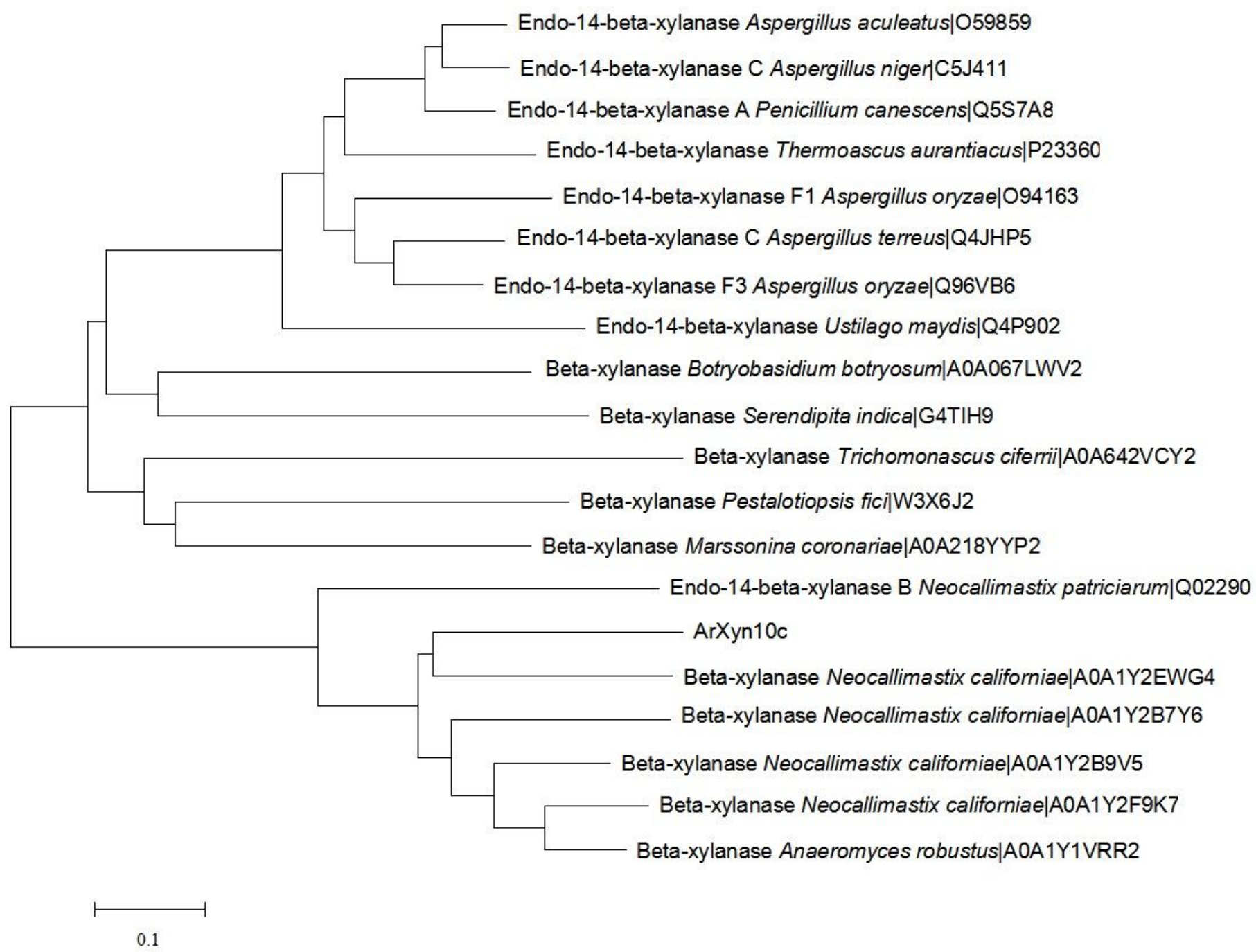

\section{Figure 1}

Phylogenetic tree of ArXyn10c20 based on protein sequence homology. 


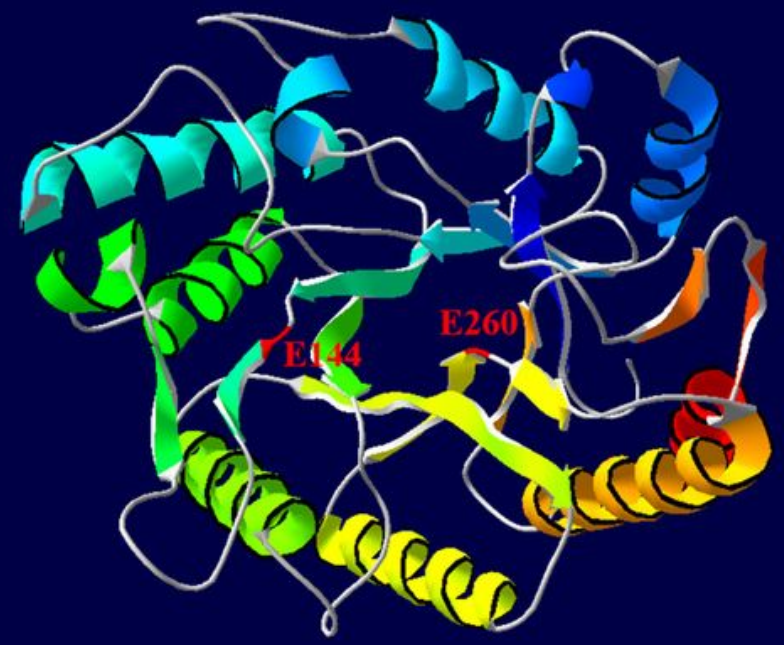

b

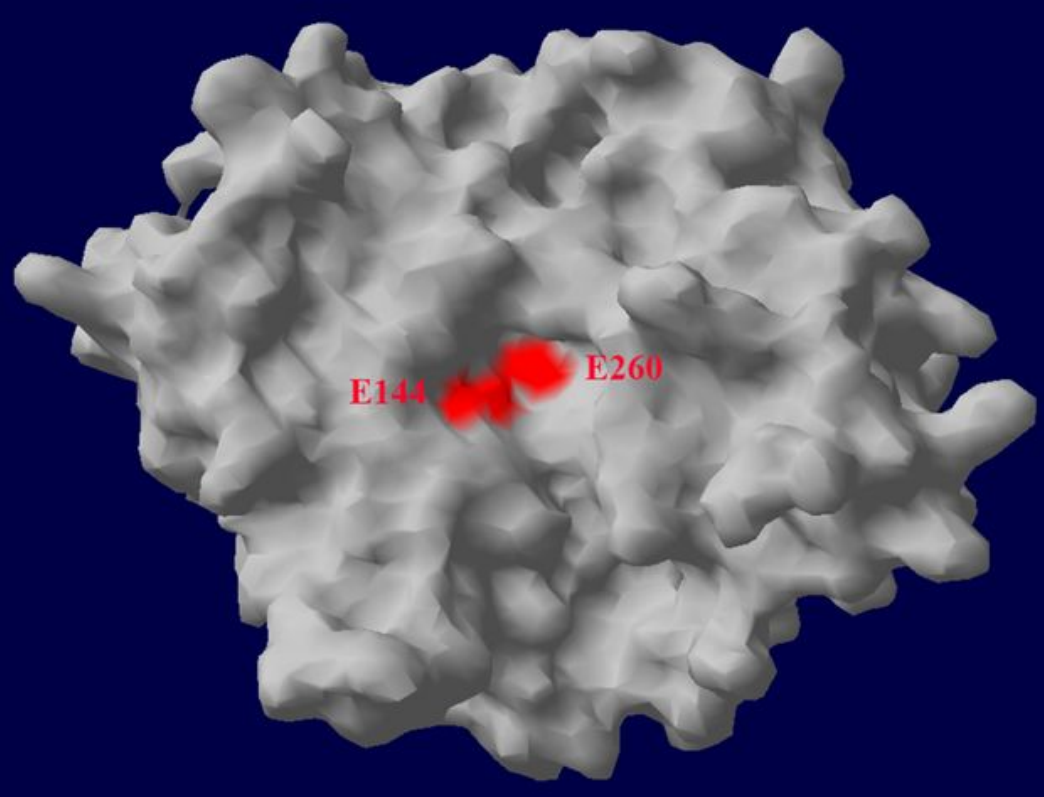

Figure 2

Homology modeling of ArXyn10c20(a) and surface structure of ArXyn10c20(b) 

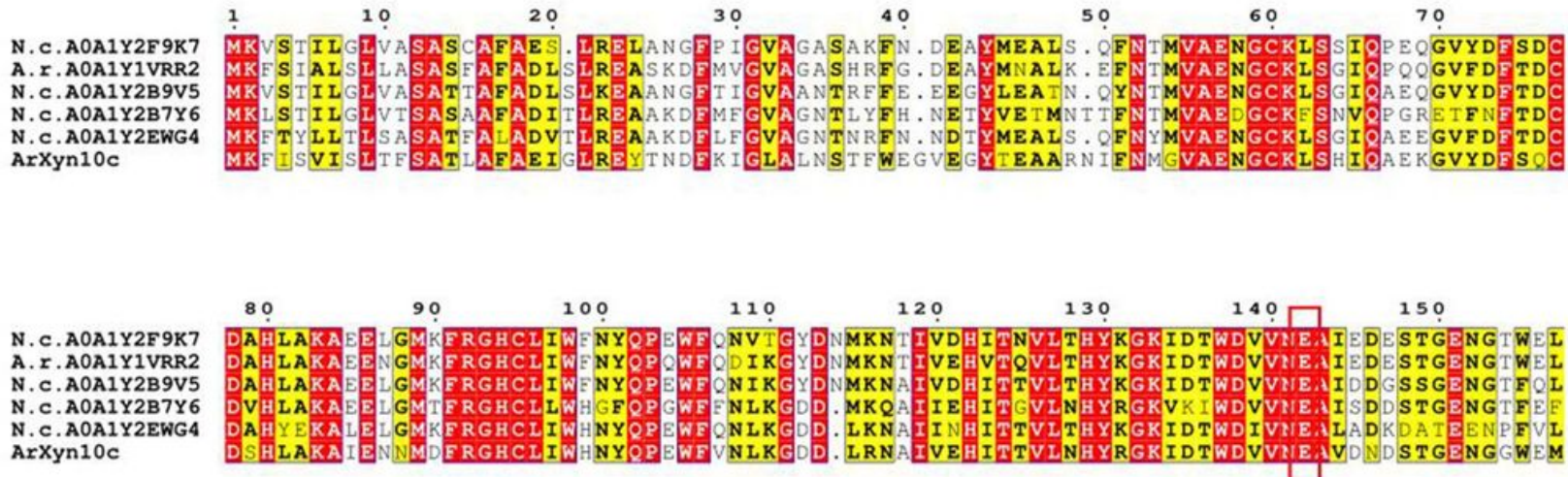

E144
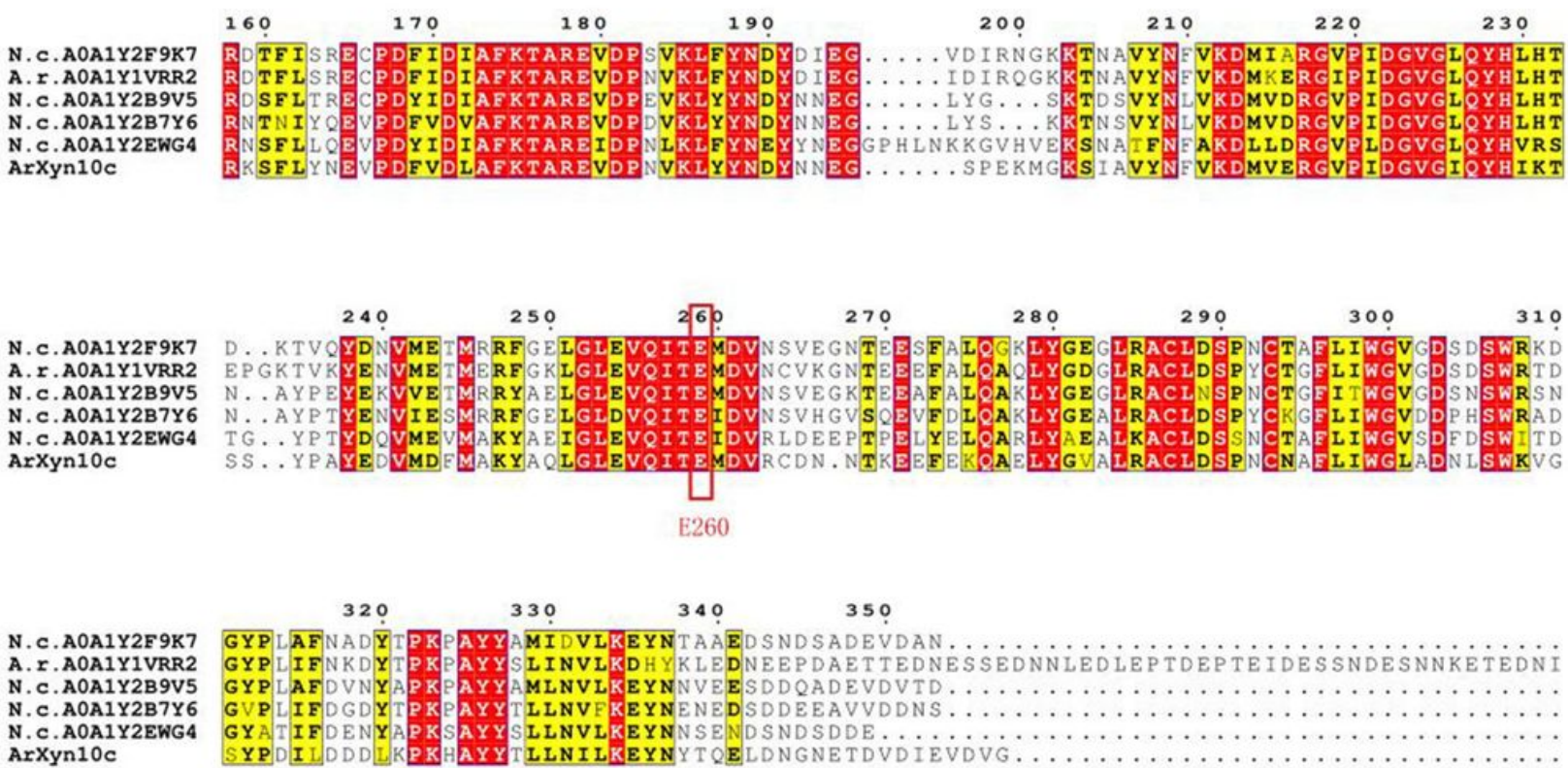

SYPDILDD D L K

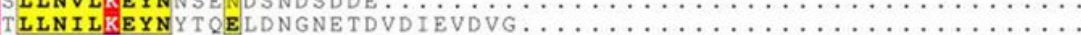

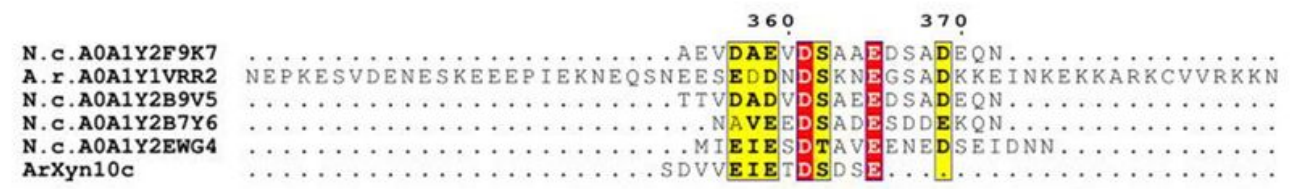

\section{Figure 3}

Multiple sequence alignment of ArXyn10c20 and GH10 xylanases derived from anaerobic rumen fungi. Abbreviation of the xylanases and Uniprot accession numbers are as follows: Neocallimastix californiae A0A1Y2B9V5 (N.c.A0A1Y2B9V5), Neocallimastix californiae A0A1Y2EWG4 (N.c.A0A1Y2EWG4), Neocallimastix californiae A0A1Y2F9K7 (N.c.A0A1Y2F9K7), Neocallimastix californiae A0A1Y2B7Y6 (N.c.A0A1Y2B7Y6), Anaeromyces robustus A0A1Y1VRR2 (A.r.A0A1Y1VRR2). 


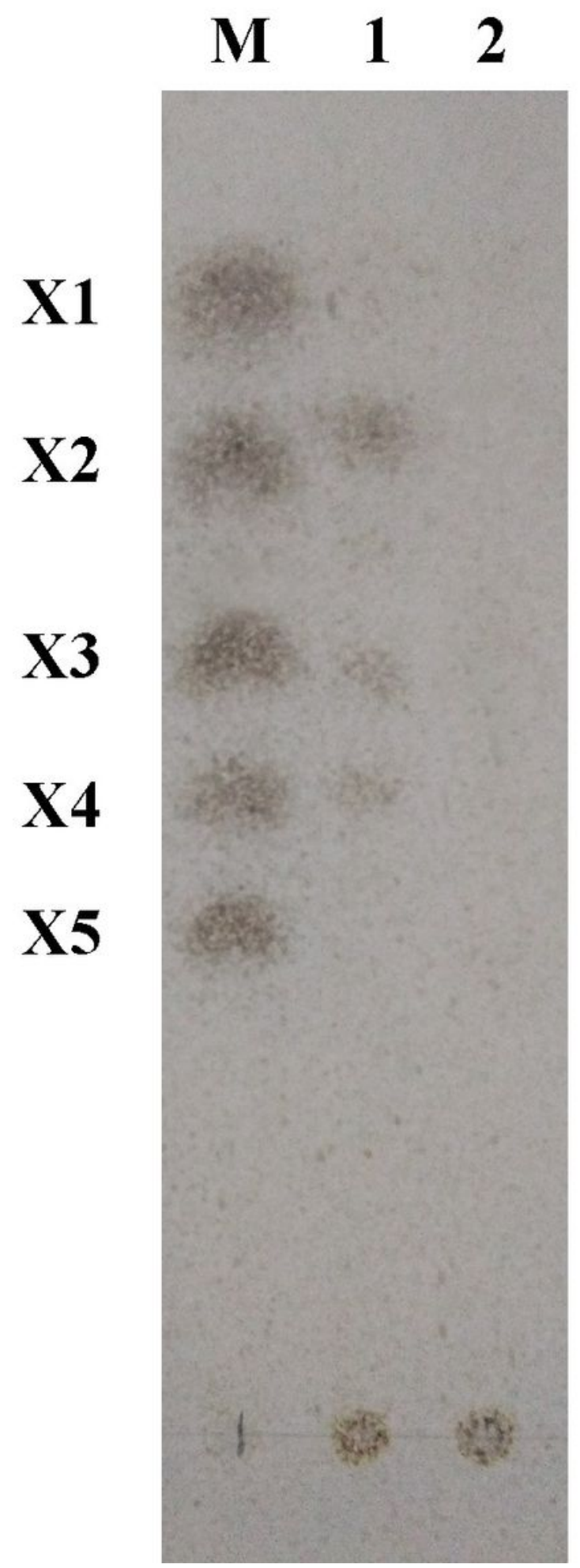

Figure 4

SDS-PAGE analysis of the purified ArXyn10c20. Lanes: M: Marker; 1: Cultured supernatant; 2. ArXyn10c20 purified by Ni-NTA; 3. ArXyn10 digested with Endo H; 4. Endo H. 

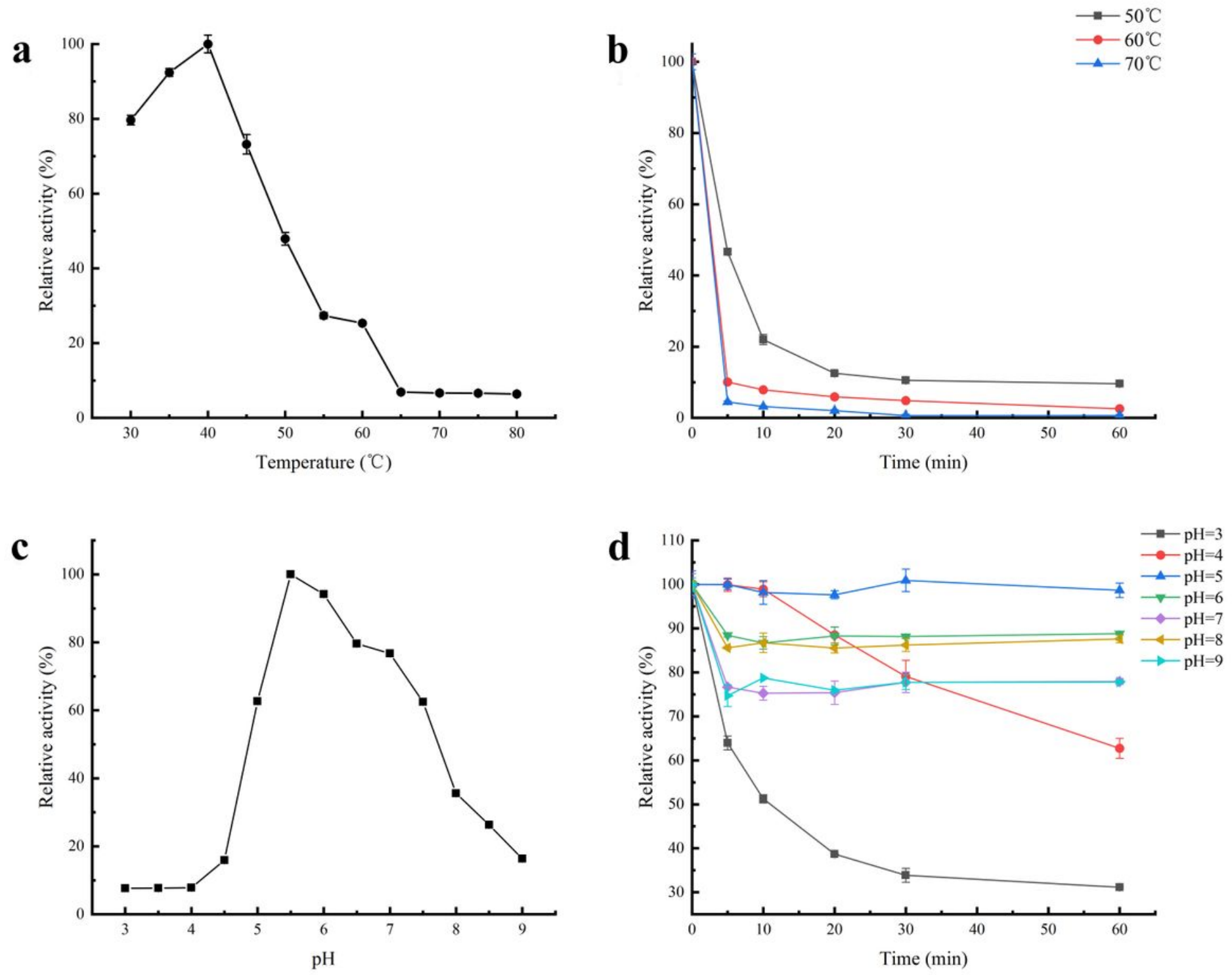

Figure 5

Effect of $\mathrm{pH}$ and temperature on the catalytic activity and stability of the ArXyn10c20. (a) Optimum temperature; (b) Thermostability; (c) Optimum pH; (d) pH stability. 


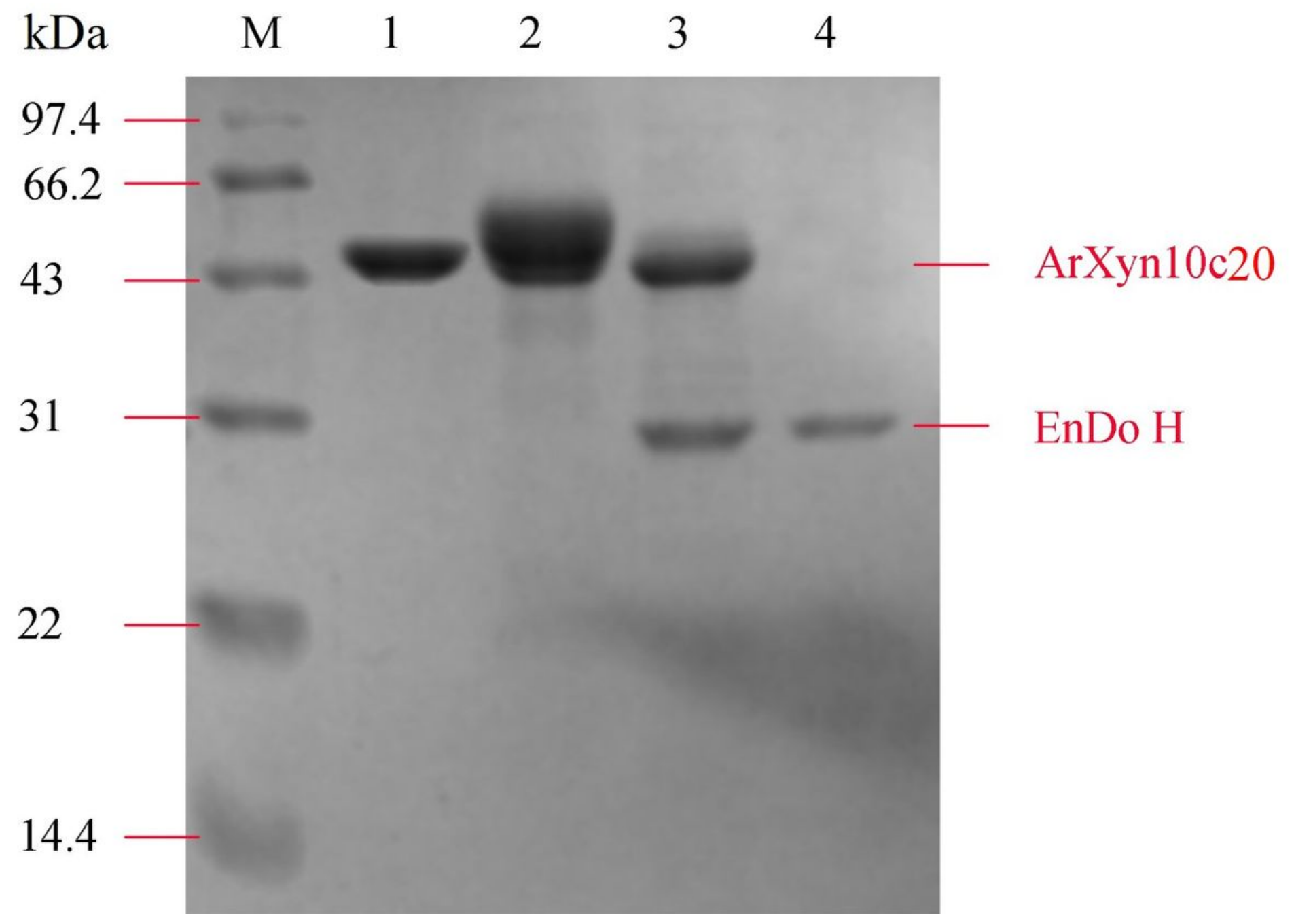

Figure 6

TLC analysis of hydrolytic products of ArXyn10c20. Lanes: M: the standard xylose (X1) and

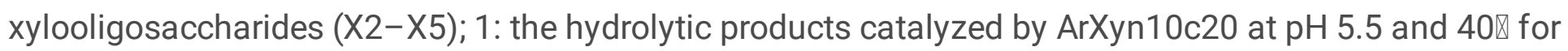
$30 \mathrm{~min} ; 2$. xylan without hydrolysis. 


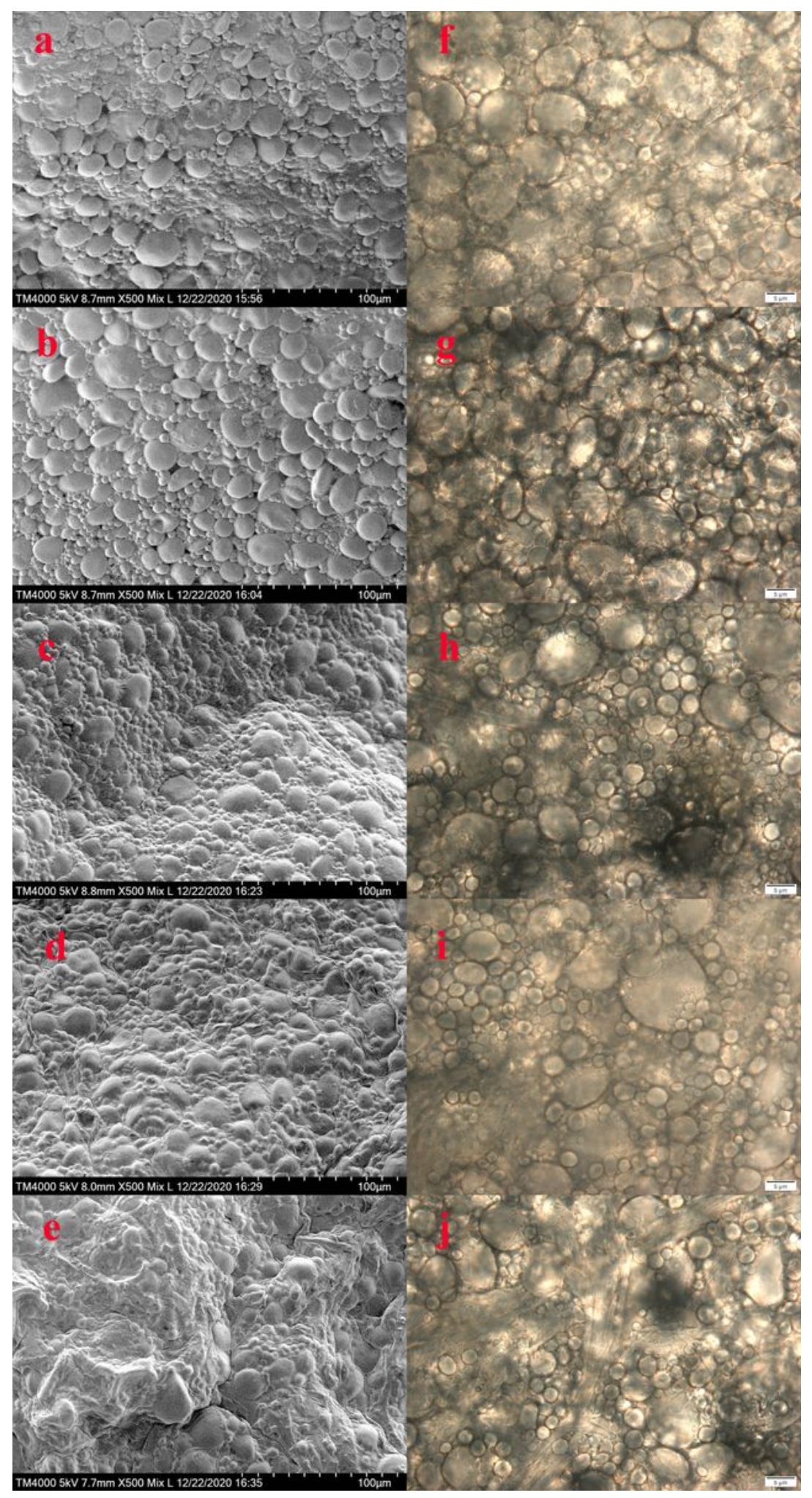

\section{Figure 7}

Effect of ArXyn10c20 on microstructure of dough. $(a, f)$ dough without ArXyn10c20 before fermentation; $(b, g)$ dough without ArXyn10c20 after fermentation; (c,h)dough with $2.5 \mathrm{mg}$ ArXyn10c20 after fermentation; (d,i)dough with $5.0 \mathrm{mg}$ ArXyn10c20 after fermentation; (e,j)dough with $7.5 \mathrm{mg}$ ArXyn10c20 after fermentation . 